\title{
Utilização de multilinhas dinâmicas para o manejo da antracnose do sorgo
}

\author{
Rodrigo Véras da Costa(1), Laércio Zambolim(2), Dagma Dionísia da Silva(1), \\ Luciano Viana Cota $^{(1)}$ e Carlos Roberto Casela(1)
}

(1)Embrapa Milho e Sorgo, Caixa Postal 285, CEP 35701-970 Sete Lagoas, MG. E-mail: veras@cnpms.embrapa.br, dagma@cnpms.embrapa.br, Ivcota@cnpms.embrapa.br, caselacarlos@hotmail.com (2)Universidade Federal de Viçosa, CEP 36570-000 Viçosa, MG. E-mail: zambolim@ufv.br

Resumo - O objetivo deste trabalho foi avaliar a eficiência do uso de multilinhas dinâmicas, por meio de misturas genéticas em populações de híbridos triplos, no manejo da antracnose do sorgo, causada pelo fungo Colletotrichum sublineolum. Foram obtidos 18 híbridos triplos a partir de sete linhagens que continham genes distintos para resistência à doença. Os 25 genótipos de híbridos e linhagens foram avaliados em campo. Verificou-se, em alguns híbridos, grau de resistência superior ao observado para a linhagem mais resistente utilizada nos cruzamentos, o que indica efeito aditivo dos genes de resistência das diferentes linhagens na composição da resistência final dos híbridos. O uso das multilinhas dinâmicas reduziu a intensidade da doença no campo e aumentou a produtividade. Essa estratégia torna possível a utilização de linhagens que apresentam características agronômicas desejáveis, mas são suscetíveis à antracnose.

Termos para indexação: Colletotrichum sublineolum, Sorghum bicolor, híbridos triplos, piramidação de genes, resistência dilatória, variabilidade genética.

\section{Use of dynamic multilines for the management of sorghum anthracnose}

\begin{abstract}
The objective of this work was to evaluate the efficiency of dynamic multilines, using genetic mixing in populations of three-way hybrids, in the management of sorghum anthracnose, caused by the fungus Colletotrichum sublineolum. Eighteen three-way hybrids were obtained from seven different lines containing genes for resistance to the disease. The 25 genotypes of hybrids and lines were evaluated in field conditions. In some hybrids, a higher resistance level was observed when compared to that of the more resistant line used in the crosses, indicating an additive effect of the resistance genes of the different lineages in the composition of the final resistance of hybrids. The use of dynamic multilines reduced the disease intensity in field and increased productivity. This strategy makes it possible to use lineages that have desirable agronomic characteristics, but are susceptible to anthracnose.
\end{abstract}

Index terms: Colletotrichum sublineolum, Sorghum bicolor, three-way hybrids, gene pyraminding, dilatory resistance, genetic variability.

\section{Introdução}

O sorgo [Sorghum bicolor (L.) Moench] é um dos cereais mais cultivados no mundo, particularmente em áreas nas quais prevalecem temperaturas elevadas e baixa precipitação. A cultura atinge elevadas produções de grãos e de forragem (Leslie \& Frederiksen, 1995). Entre os fatores que podem reduzir a produção da cultura, sobressaem-se os problemas fitossanitários. A antracnose, causada pelo fungo Colletotrichum sublineolum Henn., é considerada a doença mais importante da cultura e pode ocasionar reduções na produção de grãos e de forragem (Casela et al., 2000; Wang et al., 2006; Perumal et al., 2009; Costa et al., 2011; Pereira et al., 2011). O patógeno está presente em todas as áreas de plantio de sorgo no Brasil e pode causar perdas acima de $50 \%$, principalmente em condições de alta umidade e temperaturas entre 25 e $30^{\circ} \mathrm{C}$ (Casela et al., 2000; Costa et al., 2011; Pereira et al., 2011). Perdas por antracnose também foram relatadas em ampla faixa de condições ambientais, em outros países, o que indica a existência de diferentes ecótipos do patógeno (Frederiksen et al., 1995).

A utilização da resistência genética em cultivares comerciais é considerada a estratégia de manejo mais eficiente da antracnose. Entretanto, seu uso é dificultado pela elevada variabilidade patogênica apresentada por C. sublineolum, que determina a rápida adaptação do patógeno a cultivares resistentes (Casela \& Frederiksen, 1994; Lima \& Menezes, 2002; Chala et al., 2011; Costa et al., 2011; Pereira et al., 2011). Nos últimos anos, grande ênfase tem sido dada à busca por alternativas 
que permitam ampliar a durabilidade da resistência do sorgo à antracnose. A resistência dilatória, que atua por meio da redução da taxa de desenvolvimento da doença (Casela et al., 1993; Guimarães et al., 1998), e a identificação da dissociação de genes de virulência na população do patógeno têm sido utilizadas com esse propósito (Casela et al., 2000). Uma das alternativas para o controle de patógenos de alta variabilidade é a utilização de estratégias que aumentem a diversidade genética da população hospedeira, por meio do uso de misturas genéticas, que estabilizam a população do patógeno e previnem o surgimento ou a seleção de novas raças (Guimarães et al., 1998).

Nesse sentido, pode-se obter maior grau de diversificação da população do hospedeiro por meio da utilização de multilinhas dinâmicas, que consistem na produção de híbridos triplos a partir do cruzamento de linhagens com diferentes genes de resistência à doença (Tapsoba \& Wilson, 1999). A técnica das multilinhas dinâmicas integra atributos favoráveis da multilinha padrão e da piramidação de genes para o manejo de doenças. Com a multilinha dinâmica, o intercruzamento permite aumentar a frequência de plantas com mais de um gene de resistência, o que é característica da estratégia de piramidação de genes. Entretanto, a heterogeneidade genotípica dentro da população também é aumentada.

O objetivo deste trabalho foi avaliar a eficiência do uso de multilinhas dinâmicas, por meio de misturas genéticas em populações de híbridos triplos, no manejo da antracnose do sorgo.

\section{Material e Métodos}

Os experimentos foram conduzidos na Embrapa Milho e Sorgo, em Sete Lagoas, MG. Foram utilizadas sete linhagens-elite do programa de melhoramento de sorgo da Embrapa: quatro linhagens macho-estéreis (A, 1-4) e três restauradoras (R, 5-7) (Tabela 1). A partir das possíveis combinações, três a três, entre as sete linhagens, foram obtidas 18 combinações triplas.

Para a obtenção das combinações triplas, foi utilizado o sistema de macho-esterilidade, fundamentado no cruzamento entre linhagens macho-estéreis (A), linhagens macho-férteis (B) e linhagens restauradoras da fertilidade (R). Para tal, plantas A de uma linhagem foram cruzadas com plantas $\mathrm{B}$ de uma segunda linhagem, para produzirem a $\mathrm{F}_{1}$ estéril (híbrido simples). Para gerar os híbridos triplos, as plantas $F_{1}$ resultantes desse cruzamento foram cruzadas com plantas R de uma terceira linhagem.

Para obtenção dos seis híbridos simples $\mathrm{F}_{1}$, foram realizados cruzamentos entre as linhagens CMSXS210, CMSXS112, CMSXS215 e CMSXS221. As plantas foram semeadas em campo, em seis parcelas compostas de quatro fileiras de 5,0 m cada uma, no espaçamento de $0,9 \times 0,2 \mathrm{~m}$. Nas duas fileiras centrais de cada parcela, foi semeada a linhagem A e, nas duas laterais, a linhagem B. Para a realização dos cruzamentos, todas as panículas de cada parcela foram cobertas com sacos de papel antes do florescimento, para isolar geneticamente os materiais. No florescimento, o pólen produzido pelas plantas das fileiras com linhagens $\mathrm{R}$ foi transferido, por meio dos sacos de papel, para as plantas das linhagens A, levando a termo os cruzamentos. Ao final do ciclo, as sementes colhidas nas seis parcelas constituíram os seis híbridos simples ( $\mathrm{F}_{1}$ estéril).

A partir dos seis híbridos simples produzidos $\left(\mathrm{F}_{1}\right.$ estéril), realizou-se o cruzamento com as linhagens

Tabela 1. Linhagens e híbridos triplos de sorgo avaliados quanto à resistência à antracnose foliar.

\begin{tabular}{|c|c|}
\hline Tratamento $^{(1)}$ & Linhagem ou combinação híbrida \\
\hline 1 & CMSXS210 \\
\hline 2 & CMSXS112 \\
\hline 3 & CMSXS215 \\
\hline 4 & CMSXS221 \\
\hline 5 & CMSXS169 \\
\hline 6 & CMSXS182 \\
\hline 7 & CMSXS116 \\
\hline 8 & CMSXS210A x CMSXS112B x CMSXS169R \\
\hline 9 & CMSXS210A x CMSXS215B x CMSXS169R \\
\hline 10 & CMSXS210A x CMSXS221B x CMSXS169R \\
\hline 11 & CMSXS112A x CMSXS215B x CMSXS169R \\
\hline 12 & CMSXS112A x CMSXS221B x CMSXS169R \\
\hline 13 & CMSXS215A x CMSXS221B x CMSXS169R \\
\hline 14 & CMSXS210A x CMSXS112B x CMSXS182R \\
\hline 15 & CMSXS210A x CMSXS215B x CMSXS182R \\
\hline 16 & CMSXS210A x CMSXS221B x CMSXS182R \\
\hline 17 & CMSXS112A x CMSXS215B x CMSXS182R \\
\hline 18 & CMSXS112A x CMSXS221B x CMSXS182R \\
\hline 19 & CMSXS215A x CMSXS221B x CMSXS182R \\
\hline 20 & CMSXS210A x CMSXS112B x CMSXS116R \\
\hline 21 & CMSXS210A x CMSXS215B x CMSXS116R \\
\hline 22 & CMSXS210A x CMSXS221B x CMSXS116R \\
\hline 23 & CMSXS112A x CMSXS215B x CMSXS116R \\
\hline 24 & CMSXS112A x CMSXS221B x CMSXS116R \\
\hline 25 & CMSXS215A x CMSXS221B x CMSXS116R \\
\hline
\end{tabular}

(1) 1 a 7, linhagens; 8 a 25, híbridos triplos. A, linhagens macho-estéreis; $\mathrm{B}$, linhagens macho-férteis; $\mathrm{R}$, linhagens restauradoras da fertilidade. 
R (CMSXS169, CMSXS182 e CMSXS116), para a obtenção das 18 combinações triplas possíveis. Para tanto, foram semeadas 18 parcelas experimentais com quatro fileiras de 5,0 m cada uma, no espaçamento de 0,9x0,2 m. As duas fileiras centrais de cada parcela foram constituídas por plantas $F_{1}$ (estéreis), de cada cruzamento, e as duas fileiras laterais foram semeadas com plantas da terceira linhagem (R). As linhas constituídas pelas linhagens restauradoras foram semeadas com uma diferença de 15 dias entre si, para garantir a coincidência do florescimento entre as diferentes linhagens e os híbridos $\mathrm{F}_{1}$ a serem cruzados. Os cruzamentos foram realizados conforme descrito para a produção dos híbridos simples. As sementes resultantes dos cruzamentos, nas 18 parcelas, constituíram os 18 híbridos triplos, avaliados quanto à reação à antracnose em experimentos posteriores.

O primeiro experimento foi conduzido de dezembro de 2002 a março de 2003. Utilizou-se o delineamento experimental de blocos ao acaso, com 25 tratamentos e três repetições. Os tratamentos foram constituídos dos 18 híbridos triplos e das sete linhagens genitoras (Tabela 1). As parcelas foram constituídas de duas fileiras de 6,0 m de comprimento, no espaçamento de $0,9 \mathrm{x} 0,2 \mathrm{~m}$. O experimento foi repetido no período de março a junho de 2003, para confirmação dos resultados (segundo experimento).

Para promover o isolamento entre as parcelas, foram semeadas duas fileiras de milho imune a C. sublineolum, nas laterais e em uma das extremidades de cada parcela. A $0,5 \mathrm{~m}$ da extremidade livre das parcelas, foi semeada uma bordadura com a cultivar suscetível BR009 (Tx623), formada por fileiras de $1,0 \mathrm{~m}$ de comprimento, para atuar como fonte de inóculo. Quando necessário, foram realizadas irrigações suplementares, em toda área experimental, por aspersão convencional.

As avaliações quanto à severidade da doença foram iniciadas imediatamente após o aparecimento dos primeiros sintomas da antracnose nas folhas e continuadas em intervalos semanais, até a colheita dos experimentos. Foram avaliadas, visualmente, dez plantas de cada parcela, para cálculo da severidade média por parcela. Utilizou-se a escala diagramática estabelecida por Sharma (1983).

Ao final do ciclo cultural das linhagens e dos híbridos, foi realizada a colheita das panículas para a avaliação da produção. Foram colhidas todas as panículas de cada parcela, com exceção das presentes nas três plantas das extremidades de cada linha, consideradas como bordadura. As panículas foram etiquetadas, secas em condição ambiente e armazenadas separadamente. Foram avaliados: peso de panícula, produção de grãos e peso de 1.000 grãos, em cada parcela.

Os dados de percentagem de área foliar lesionada, obtidos de cada parcela, foram utilizados para calcular a área abaixo da curva de progresso da doença (AACPD), segundo Shaner \& Finney (1977), com auxílio do programa AVACPD (Torres \&Ventura, 1991). Os valores de AACPD, peso de panícula, produção de grãos e peso de 1.000 grãos foram submetidos à análise de variância, e as médias dos tratamentos foram comparadas com o teste de Tukey, a $1 \%$ de probabilidade, tendo-se utilizado o programa Sisvar 5.1 (Ferreira, 2008).

Foram determinados os coeficientes de correlação de Pearson entre produção e severidade da doença e entre AACPD, produção de grãos, peso de 1.000 grãos e peso de panícula.

O nível de resistência foi determinado por meio da avaliação dos valores da AACPD de linhagens e híbridos, em cada experimento. Para determinar os ganhos em produtividade obtidos em função da resistência resultante da utilização das multilinhas dinâmicas, considerou-se a produção de grãos e o peso de 1.000 grãos e de panículas, em relação às linhagens componentes dos híbridos.

\section{Resultados e Discussão}

No primeiro experimento, seis combinações triplas, entre as 18 avaliadas, destacaram-se com menores valores de AACPD, tendo sido considerados resistentes os híbridos 8, 9, 11, 15, 16 e 21 (Tabela 2). As demais combinações foram consideradas moderadamente resistentes. Entre as linhagens, apenas a CMSXS169 foi classificada como resistente. As linhagens CMSXS112, CMSXS221 e CMSXS210 constituíram o grupo dos materiais mais suscetíveis à doença. As demais linhagens apresentaram valores intermediários de AACPD, tendo sido consideradas moderadamente resistentes.

A composição das combinações triplas permitiu avaliar a contribuição de algumas linhagens quanto ao grau de resistência apresentado. Das seis combinações em que a linhagem R CMSXS169 foi utilizada nos cruzamentos, três foram classificadas como resistentes: os híbridos triplos 8, 9 e 11. Isso evidenciou a elevada 
contribuição dessa linhagem para o nível de resistência desses materiais (Tabela 2). Nas outras linhagens R, CMSXS116 e CMSXS182, a percentagem de combinações triplas resistentes foi de 33 e 16\%, respectivamente.

Embora esteja clara a elevada contribuição da linhagem CMSXS169 para a resistência dos híbridos, outras combinações de linhagens apresentaram grau de resistência superior ao dessas mesmas linhagens, quando utilizadas separadamente (Figura 1). Algumas das combinações resultantes do cruzamento entre as linhagens CMSXS210, CMSXS221, CMSXS112, CMSXS116 e CMSXS182 foram classificadas como resistentes. Já as linhagens CMSXS210, CMSXS221 e CMSXS112 foram classificadas como suscetíveis, e as linhagens CMSXS182 e CMSXS116 como intermediárias.

Tabela 2. Área abaixo da curva de progresso da doença (AACPD), peso de 1.000 grãos (P1.000), produção de grãos e peso de panícula, nos 25 tratamentos, no experimento $1^{(1)}$.

\begin{tabular}{|c|c|c|c|c|}
\hline Tratamento $^{(2)}$ & AACPD & $\begin{array}{c}\text { P1.000 } \\
(\mathrm{g})\end{array}$ & $\begin{array}{l}\text { Produção de } \\
\text { grãos (kg) }\end{array}$ & $\begin{array}{c}\text { Peso de } \\
\text { panícula }(\mathrm{kg})\end{array}$ \\
\hline 2 & $2.364,58 \mathrm{a}$ & $17,383 \mathrm{hi}$ & $0,775 \mathrm{a}-\mathrm{c}$ & $1,076 a-c$ \\
\hline 4 & $2.106,57 \mathrm{ab}$ & $17,964 \mathrm{~g}-\mathrm{i}$ & $0,551 \mathrm{bc}$ & $0,801 \mathrm{~b}$ \\
\hline 1 & $2.045,50 \mathrm{ab}$ & $14,300 \mathrm{i}$ & $0,909 a-c$ & $1,268 \mathrm{a}-\mathrm{c}$ \\
\hline 3 & $1.350,17 \mathrm{bc}$ & $19,856 \mathrm{f}-\mathrm{h}$ & $1,382 \mathrm{a}-\mathrm{c}$ & $1,956 \mathrm{a}-\mathrm{c}$ \\
\hline 24 & $1.095,73 \mathrm{~cd}$ & $20,002 \mathrm{e}-\mathrm{h}$ & $1,358 \mathrm{a}-\mathrm{c}$ & $1,861 \mathrm{a}-\mathrm{c}$ \\
\hline 18 & $1.005,92 \mathrm{~cd}$ & $20,118 \mathrm{e}-\mathrm{h}$ & $1,195 \mathrm{a}-\mathrm{c}$ & $1,674 a-c$ \\
\hline 7 & $800,23 \mathrm{~cd}$ & 17,461hi & $0,649 a-c$ & $0,934 b c$ \\
\hline 22 & $750,60 \mathrm{~cd}$ & $23,096 \mathrm{c}-\mathrm{g}$ & $1,596 a-c$ & $2,321 \mathrm{a}-\mathrm{c}$ \\
\hline 14 & $688,07 \mathrm{~cd}$ & $22,881 \mathrm{~d}-\mathrm{h}$ & $1,688 \mathrm{a}-\mathrm{c}$ & $2,339 a-c$ \\
\hline 17 & $682,75 \mathrm{~cd}$ & $25,428 \mathrm{a}-\mathrm{e}$ & $1,585 \mathrm{a}-\mathrm{c}$ & $2,096 \mathrm{a}-\mathrm{c}$ \\
\hline 19 & $646,50 \mathrm{~cd}$ & $24,996 a-f$ & $1,996 \mathrm{ab}$ & $2,642 \mathrm{ab}$ \\
\hline 6 & $625,20 \mathrm{~cd}$ & $19,471 \mathrm{f}-\mathrm{i}$ & $0,519 \mathrm{c}$ & $0,753 b$ \\
\hline 20 & $621,47 \mathrm{~cd}$ & $23,620 b-f$ & $2,084 \mathrm{a}$ & $2,743 \mathrm{a}$ \\
\hline 12 & $527,68 \mathrm{~cd}$ & $28,823 \mathrm{ab}$ & $1,665 \mathrm{a}-\mathrm{c}$ & $2,113 a-c$ \\
\hline 23 & $517,37 \mathrm{~cd}$ & $24,773 a-f$ & $1,919 \mathrm{a}-\mathrm{c}$ & $2,604 \mathrm{ab}$ \\
\hline 25 & $495,72 \mathrm{~cd}$ & $26,491 \mathrm{a}-\mathrm{d}$ & $1,217 \mathrm{a}-\mathrm{c}$ & $1,709 \mathrm{a}-\mathrm{c}$ \\
\hline 10 & $462,17 \mathrm{~cd}$ & $27,034 a-d$ & $2,022 \mathrm{a}$ & $2,684 \mathrm{ab}$ \\
\hline 13 & $437,57 \mathrm{~cd}$ & $28,525 a-c$ & $1,099 \mathrm{a}-\mathrm{c}$ & $1,553 \mathrm{a}-\mathrm{c}$ \\
\hline 15 & $414,42 d$ & $24,057 \mathrm{a}-\mathrm{f}$ & $1,662 \mathrm{a}-\mathrm{c}$ & $2,409 a-c$ \\
\hline 11 & $351,23 d$ & $29,369 \mathrm{a}$ & $1,397 \mathrm{a}-\mathrm{c}$ & $2,008 \mathrm{a}-\mathrm{c}$ \\
\hline 8 & $350,78 d$ & $27,371 \mathrm{a}-\mathrm{d}$ & $1,889 \mathrm{a}-\mathrm{c}$ & $2,628 \mathrm{ab}$ \\
\hline 21 & $350,33 d$ & $24,693 a-f$ & $1,655 \mathrm{a}-\mathrm{c}$ & $2,384 a-c$ \\
\hline 9 & $349,92 d$ & $27,304 a-d$ & $1,567 \mathrm{a}-\mathrm{c}$ & $2,248 \mathrm{a}-\mathrm{c}$ \\
\hline 16 & $344,13 d$ & $22,254 \mathrm{~d}-\mathrm{h}$ & $0,737 \mathrm{a}-\mathrm{c}$ & $1,087 \mathrm{a}-\mathrm{c}$ \\
\hline 5 & $277,12 \mathrm{~d}$ & $26,623 a-d$ & $1,063 \mathrm{a}-\mathrm{c}$ & $1,600 \mathrm{a}-\mathrm{c}$ \\
\hline CV $(\%)$ & 32 & 7 & 29 & 25 \\
\hline
\end{tabular}

${ }^{(1)}$ Médias seguidas de letras iguais não diferem pelo teste de Tukey, a $1 \%$ de probabilidade. ${ }^{(2)}$ Os tratamentos estão listados na Tabela 1.
A correlação entre AACPD e peso de 1.000 grãos foi superior à observada entre AACPD e peso de panícula e produção de grãos $(-0,79,-0,5$ e $-0,47$, respectivamente). De modo geral, as linhagens mais resistentes apresentaram maior peso de 1.000 grãos.

No segundo experimento, foram observados valores mais baixos de AACPD, decorrentes de temperaturas mais baixas e da menor precipitação no período de condução do experimento (Figura 1). A precipitação média diária observada no primeiro experimento foi de $73,4 \mathrm{~mm}$ e de apenas $0,38 \mathrm{~mm}$ no segundo experimento. A temperatura média diária foi de 23,4 e $19,4^{\circ} \mathrm{C}$ para os experimentos 1 e 2 , respectivamente. As condições que favorecem o desenvolvimento da antracnose do sorgo são caracterizadas por altas temperaturas e precipitações (Frederiksen, 2000).

De acordo com os resultados de AACPD, o maior grau de resistência foi obtido no tratamento 15 , que correspondeu ao híbrido triplo resultante da combinação das linhagens CMSXS210, CMSXS215 e CMSXS182
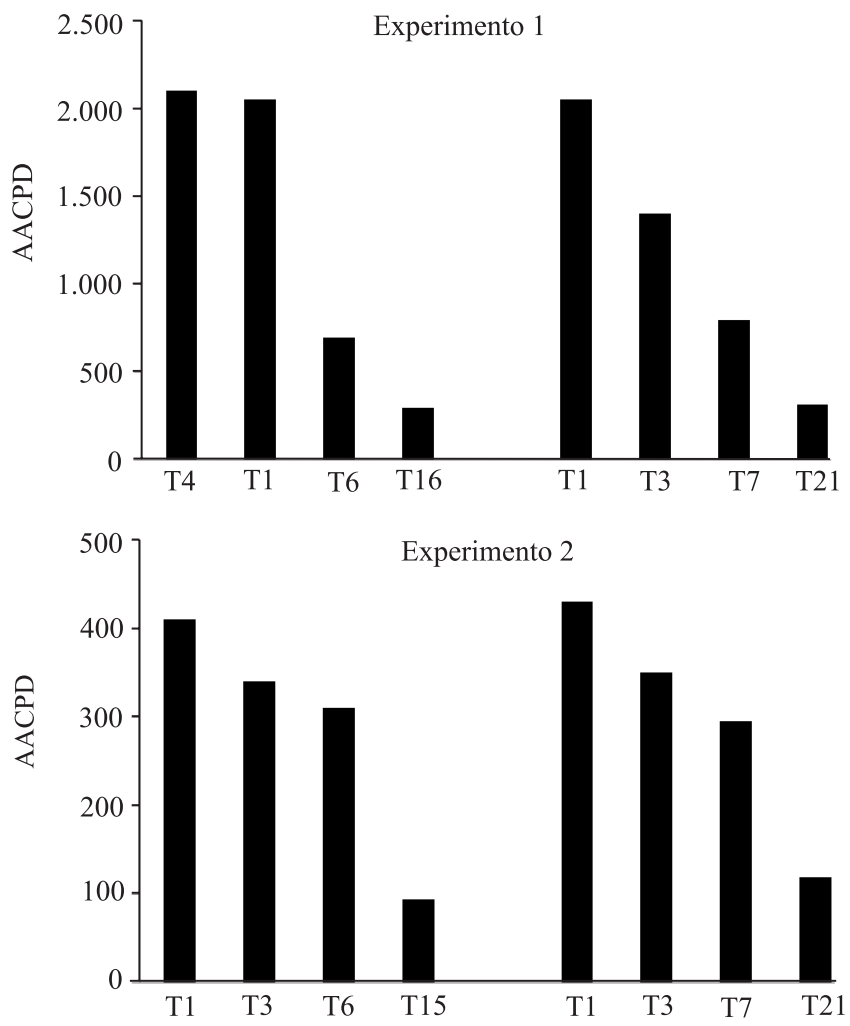

Figura 1. Área abaixo da curva de progresso da antracnose do sorgo (AACPD). Tratamentos seguidos por números de 1 a 7 (T1 a T7) referem-se a linhagens, e os demais a híbridos triplos, conforme Tabela 1. 
(Tabela 3). Em seguida, vieram os tratamentos 5, 6, $7,8,9,10,11,12,13,17,19,20,21,23$ e 25 , que não diferiram significativamente do tratamento 15 . Os tratamentos 2, 4 e 18 apresentaram-se como os mais suscetíveis, e os demais apresentaram nível intermediário de resistência. Entre as combinações triplas, 16 foram classificadas como resistentes e uma como suscetível. Todas as combinações triplas em que a linhagem CMSXS169 tenha participado nos cruzamentos foram classificadas como resistentes. As combinações resistentes formadas a partir das linhagens R CMSXS182 e CMSXS116 representaram 50 e $66 \%$, respectivamente, do total de combinações formadas com essas linhagens. Todas as combinações triplas classificadas como resistentes apresentavam pelo menos uma linhagem genitora também classificada como resistente.

Tabela 3. Área abaixo da curva de progresso da doença (AACPD), peso de 1.000 grãos (P1.000), produção de grãos e peso de panícula, nos 25 tratamentos, no experimento $2^{(1)}$.

\begin{tabular}{|c|c|c|c|c|}
\hline Tratamento $^{(2)}$ & AACPD & $\begin{array}{c}\mathrm{P} 1.000 \\
(\mathrm{~g})\end{array}$ & $\begin{array}{c}\text { Produção de } \\
\text { grãos }(\mathrm{kg})\end{array}$ & $\begin{array}{c}\text { Peso de } \\
\text { panícula }(\mathrm{kg})\end{array}$ \\
\hline 2 & $1.725,97 \mathrm{a}$ & $17,93 \mathrm{e}-\mathrm{g}$ & $0,58 \mathrm{fg}$ & $0,92 \mathrm{f}-\mathrm{h}$ \\
\hline 4 & $1.289,17 \mathrm{~b}$ & $20,79 d-f$ & $0,61 \mathrm{fg}$ & $0,92 \mathrm{f}-\mathrm{h}$ \\
\hline 18 & $788,90 \mathrm{c}$ & $19,55 \mathrm{e}-\mathrm{g}$ & $1,13 \mathrm{ef}$ & $1,57 \mathrm{e}-\mathrm{g}$ \\
\hline 24 & $627,43 \mathrm{~cd}$ & $23,51 \mathrm{c}-\mathrm{f}$ & $1,27 \mathrm{~d}-\mathrm{f}$ & $1,71 \mathrm{~d}-\mathrm{g}$ \\
\hline 1 & $413,00 \mathrm{de}$ & $23,75 \mathrm{c}-\mathrm{f}$ & $1,35 \mathrm{c}-\mathrm{f}$ & $1,94 \mathrm{~b}-\mathrm{f}$ \\
\hline 16 & $392,70 d-f$ & $24,35 b-e$ & $1,43 \mathrm{c}-\mathrm{f}$ & $1,95 \mathrm{~b}-\mathrm{f}$ \\
\hline 14 & $385,70 \mathrm{~d}-\mathrm{f}$ & $26,10 a-d$ & $1,79 a-e$ & $2,34 \mathrm{a}-\mathrm{e}$ \\
\hline 3 & $338,57 \mathrm{~d}-\mathrm{f}$ & $23,92 \mathrm{c}-\mathrm{f}$ & $1,36 \mathrm{c}-\mathrm{f}$ & $1,81 \mathrm{c}-\mathrm{g}$ \\
\hline 22 & $324,33 \mathrm{~d}-\mathrm{f}$ & $27,36 a-c$ & $1,67 \mathrm{~b}-\mathrm{e}$ & $2,16 \mathrm{~b}-\mathrm{e}$ \\
\hline 6 & $305,43 \mathrm{ef}$ & $13,74 \mathrm{~g}$ & $0,06 \mathrm{~g}$ & $0,23 \mathrm{~h}$ \\
\hline 20 & $303,10 \mathrm{ef}$ & $26,29 a-d$ & $1,78 \mathrm{a}-\mathrm{e}$ & $2,33 a-e$ \\
\hline 7 & $291,20 \mathrm{ef}$ & $17,62 \mathrm{fg}$ & $0,07 \mathrm{~g}$ & $0,28 \mathrm{~h}$ \\
\hline 12 & $289,80 \mathrm{ef}$ & $28,13 \mathrm{a}-\mathrm{c}$ & $1,53 \mathrm{~b}-\mathrm{e}$ & $2,02 \mathrm{~b}-\mathrm{e}$ \\
\hline 23 & $235,43 \mathrm{ef}$ & $27,52 \mathrm{a}-\mathrm{c}$ & $2,23 a-c$ & $2,79 a-c$ \\
\hline 17 & $233,33 \mathrm{ef}$ & $28,05 \mathrm{a}-\mathrm{c}$ & $2,25 a-c$ & $2,82 a-c$ \\
\hline 25 & $208,83 \mathrm{ef}$ & $28,13 \mathrm{a}-\mathrm{c}$ & $2,13 a-d$ & $2,67 a-d$ \\
\hline 19 & $186,55 \mathrm{ef}$ & $28,84 \mathrm{a}-\mathrm{c}$ & $1,91 \mathrm{a}-\mathrm{e}$ & $2,39 \mathrm{a}-\mathrm{e}$ \\
\hline 10 & $166,83 \mathrm{ef}$ & $28,99 \mathrm{a}-\mathrm{c}$ & $1,63 \mathrm{~b}-\mathrm{e}$ & $2,16 \mathrm{~b}-\mathrm{e}$ \\
\hline 9 & $163,80 \mathrm{ef}$ & $30,86 \mathrm{a}$ & $1,98 \mathrm{a}-\mathrm{e}$ & $2,52 \mathrm{a}-\mathrm{e}$ \\
\hline 8 & $157,50 \mathrm{ef}$ & $28,38 \mathrm{a}-\mathrm{c}$ & $1,82 \mathrm{a}-\mathrm{e}$ & $2,38 \mathrm{a}-\mathrm{e}$ \\
\hline 11 & $145,02 \mathrm{ef}$ & $30,52 \mathrm{ab}$ & $2,01 \mathrm{a}-\mathrm{e}$ & $2,49 a-e$ \\
\hline 13 & $141,87 \mathrm{ef}$ & $31,37 \mathrm{a}$ & $2,04 a-d$ & $2,57 \mathrm{a}-\mathrm{e}$ \\
\hline 21 & $127,17 \mathrm{ef}$ & $28,67 \mathrm{a}-\mathrm{c}$ & $2,61 \mathrm{a}$ & $3,26 \mathrm{a}$ \\
\hline 5 & $95,78 \mathrm{ef}$ & $28,67 \mathrm{a}-\mathrm{c}$ & $0,55 \mathrm{fg}$ & $0,82 \mathrm{gh}$ \\
\hline 15 & $84,23 \mathrm{f}$ & $29,48 \mathrm{a}-\mathrm{c}$ & $2,34 \mathrm{ab}$ & $2,94 \mathrm{ab}$ \\
\hline$\overline{\mathrm{CV}}(\%)$ & 23 & 6 & 16 & 14 \\
\hline
\end{tabular}

${ }^{(1)}$ Médias seguidas de letras iguais não diferem pelo teste de Tukey, a $1 \%$ de probabilidade. ${ }^{(2)}$ Os tratamentos estão listados na Tabela 1.
Entretanto, o valor de AACPD observado nas linhagens foi, em geral, maior que o observado nas combinações triplas das quais elas participaram, o que, mais uma vez, evidenciou o efeito positivo das combinações no que se refere à resistência (Figura 1). A combinação das linhagens CMSXS210, CMSXS215 e CMSXS182 apresentou o mais elevado grau de resistência, entre todos os tratamentos avaliados, enquanto as linhagens CMSXS210 e CMSXS215 foram classificadas como intermediárias, e a CMSXS182 como resistente (Tabela 3 ).

As correlações entre AACPD e produção de grãos, peso de 1.000 grãos e peso de panícula foram muito próximas, com valores de $0,62,0,68$, e 0,67 , respectivamente. Isso pode ser atribuído aos altos coeficientes de correlação observados entre as variáveis de produção: 0,98 entre peso de panícula e peso de 1.000 grãos; 0,99 entre peso de panícula e produção de grãos; e 0,98 entre produção de grãos e peso de 1.000 grãos. As linhagens mais resistentes apresentaram maior produção de grãos, peso de 1.000 grãos e peso de panícula.

Um gene na planta que confira resistência a um grupo de indivíduos na população do patógeno, ainda que com menor eficiência, pode ter valor quando utilizado em estratégia de manejo da doença apropriada. Dessa forma, foi possível observar combinações triplas, neste trabalho, com alto grau de resistência à antracnose foliar, mesmo quando obtidas a partir do cruzamento de linhagens classificadas como suscetíveis e intermediárias. Buiate et al. (2010) verificaram que a combinação tripla formada por uma linhagem de sorgo com resistência vertical completa, uma suscetível a todos os isolados e outra suscetível a apenas um isolado foi suscetível a um único isolado de C. sublineolum. Resultado semelhante foi observado por Silva et al. (2008), na avaliação da reação à antracnose de linhagens-elite de sorgo e híbridos simples obtidos pelo cruzamento dessas linhagens, em condições de campo e casa de vegetação.

Observou-se que, embora o grau de resistência das combinações seja definido principalmente pela linhagem mais resistente, as linhagens mais suscetíveis também contribuem para a resistência final do híbrido. Isso pode ser constatado pelo fato de o híbrido com mais alto grau de resistência ter sido mais resistente que a linhagem mais resistente. Esse resultado é indicativo de efeito positivo e aditivo da combinação de linhagens 
em um único genótipo, em que cada combinação contribui com seus genes para o grau de resistência final no híbrido resultante. Esse é o caso do híbrido triplo resultante da combinação das linhagens CMSXS210, CMSXS221 e CMSXS182, no experimento 1. Nesse híbrido, o valor de AACPD foi de 344,13, enquanto os valores para cada uma dessas linhagens foram de: $2.045,50,2.106,57$, e 625,20 , respectivamente. Houve, portanto, redução de aproximadamente $50 \%$ na $\mathrm{AACPD}$, em comparação à observada na linhagem mais resistente. O mesmo foi observado nos tratamentos 15 e 21 deste experimento. No segundo experimento, o número de combinações resistentes foi maior, o que resultou em maior número de casos em que o grau de resistência nas combinações foi superior ao das linhagens separadamente (Tabela 3). Esses resultados concordam com os de Buiate et al. (2010), que observaram alto grau de complementariedade entre as linhagens parentais de 39 híbridos de sorgo que apresentavam as linhagens genitoras conhecidas. Estes autores avaliaram 150 genótipos de sorgo e evidenciaram a ocorrência de alelos para resistência vertical e para resistência horizontal. Efeito semelhante foi observado com a ferrugem do milheto, em que o gene $R r_{1}$ contribuiu com a resistência a indivíduos na população do patógeno, mesmo sendo menos eficiente que os genes presentes em outros híbridos (Tapsoba \& Wilson, 1999). A diversificação de genes de resistência a doenças, na população hospedeira, tem sido eficiente no manejo de epidemias causadas por muitos patógenos foliares, em geral pelo uso de multilinhas e de misturas de cultivares (Sitch \& Whittington, 1983; Pyndji \& Trutmann, 1992; Botelho et al., 2011).

Efeito favorável de misturas físicas de cultivares para o manejo da mancha-angular do feijoeiro foi relatado por Pyndji \& Trutmann (1992). Esses resultados são indicativos de que o efeito das combinações de linhagens em híbridos triplos pode ser semelhante ao observado nas multilinhas e nas misturas físicas, embora variem em intensidade.

Em um sistema de mistura de cultivares, ou multilinha padrão, o número de genótipos possíveis é igual ao número de linhagens que o compõe. No sistema de multilinhas dinâmicas, obtidas pelo cruzamento triplo de linhagens com diferentes genes de resistência, o número teórico de genótipos $(\mathrm{G})$, ao se considerar a ausência de ligação entre os locos de resistência, pode ser descrito como $\mathrm{G}=3^{\mathrm{x}}$, em que $\mathrm{x}$ é o número de genes de resistência (Tapsoba \& Wilson,
1999). O intercruzamento de três linhagens aumenta a frequência deplantas commaisdeum genederesistência, o que é característica da estratégia de piramidação de genes. Além disso, a heterogeneidade genotípica da população é aumentada, o que é característica da estratégia de multilinhas (Wilson, 1993). Essas características, em conjunto, podem explicar o efeito semelhante das técnicas mencionadas.

Existem poucos trabalhos sobre a utilização de multilinhas dinâmicas com híbridos triplos. Tapsoba \& Wilson (1999) usaram diferentes híbridos de milheto para desenvolver três categorias de misturas do hospedeiro: mistura física, populações oriundas de acasalamento ao acaso e mistura de híbridos simples e triplos, o que representou diferentes níveis de complexidade de resistência, por meio do aumento da heterogeneidade das populações e da piramidação de genes de resistência nas populações heterogêneas. Segundo estes autores, os valores de AACPD para misturas de acasalamento ao acaso e misturas de cruzamentos foram consistentemente menores que a média de seus componentes, com reduções que variaram de 12 a $71 \%$. No presente trabalho, os valores de AACPD foram significativamente menores em comparação à média dos componentes e à das linhagens mais resistentes utilizadas nas combinações, à exceção das combinações nas quais a linhagem CMSXS169 foi um dos componentes.

Os mesmos fatores epidemiológicos propostos para explicar a eficiência das misturas de cultivares e multilinhas podem ser aplicados para as multilinhas dinâmicas. $\mathrm{O}$ uso de misturas de linhagens no controle de doenças em plantas pressupõe a ocorrência de, pelo menos, dois mecanismos básicos: prevenção do fluxo de genes de virulência, o que reduz a dispersão de inóculo, e diminuição da unidade suscetível dentro do campo, o que atua como barreira física à dispersão de inóculo (Lannou \& Mundt, 1996; Ntahimpera et al., 1996; Guimarães et al., 1998). A vantagem das multilinhas dinâmicas é o aumento do número de fenótipos resistentes por meio das possíveis combinações dos genes de resistência provenientes das três linhagens em um único genótipo (Tapsoba \& Wilson, 1999). De acordo com estes autores, em combinações triplas obtidas a partir de linhagens com diferentes genes de resistência, $25 \%$ dos indivíduos na população podem ter genes de resistência oriundos das três linhagens, $50 \%$ podem ter genes de dois pais e $25 \%$ podem ter genes de resistência de um pai apenas. Isso pode 
explicar as variações no nível de resistência de algumas combinações triplas em que linhagens resistentes, como CMSXS169, foram utilizadas nos cruzamentos.

Houve correlação negativa entre AACPD e peso de 1.000 grãos, no experimento 1, e entre AACPD e peso de 1.000 grãos, produção de grãos e peso de panícula, no experimento 2. Esses resultados evidenciam o efeito mais pronunciado da doença na fase de enchimento de grãos.

O efeito positivo das combinações, que resultou em grau mais elevado de resistência que o observado nas linhagens separadamente, também foi verificado na produção de grãos. As combinações triplas classificadas como resistentes apresentaram pesos de 1.000 grãos, produção de grãos e peso de panícula maiores que os das linhagens puras (Figura 1). O tratamento 11 (combinação das linhagens CMSXS112, CMSXS215 e CMSXS169), no experimento 1, apresentou aumento de 10,33 e $41 \%$ em relação ao peso de 1.000 grãos, quando comparado às linhagens CMSXS169, CMSXS210 e CMSXS112, respectivamente. Aumento significativo também foi observado nos demais componentes da produção. A linhagem CMSXS169, que apresentou a maior resistência no experimento $1 \mathrm{e}$ a segunda maior no experimento 2, produziu menos que as combinações triplas das quais participou, incluindo aquelas classificadas como intermediárias. Segundo Wilson et al. (1994) e Tapsoba \& Wilson (1999), a redistribuição e a piramidação de genes de resistência, além do aumento da heterogeneidade da resistência, como resultado do intercruzamento, são as prováveis razões dessa vantagem das combinações triplas.

Estudos adicionais são importantes para monitorar a flutuação populacional do patógeno, a fim de determinar quais fenótipos predominam em uma população heterogênea, a possibilidade de surgimento ou de seleção de novos fenótipos virulentos e o tempo de vida útil desses híbridos. Deve-se avaliar, também, o comportamento de outras combinações triplas no manejo de doenças diferentes e selecionar as que apresentem maior uniformidade quanto a outras características agronômicas.

\section{Conclusões}

1. A linhagem CMSXS169 é resistente a Colletotrichum sublineolum e apresenta potencial para participar em cruzamentos para formação de híbridos com alta resistência à antracnose foliar.
2. A utilização de populações geneticamente heterogêneas quanto à resistência à antracnose foliar do sorgo, por meio de multilinhas dinâmicas, é altamente eficiente para o manejo da doença.

3. Além de reduzir a intensidade da doença no campo, estabilizar a população do patógeno e promover incrementos significativos na produção, a estratégia de multilinhas dinâmicas torna possível a utilização de linhagens que apresentam características agronômicas desejáveis, mas que são suscetíveis à antracnose.

\section{Referências}

BOTELHO, F.B.S.; RAMALHO, M.A.P.; ABREU, A. de F.B.; ROSA, H.J.A. Multiline as a strategy to reduce damage caused by Colletotrichum lindemuthianum in common bean. Journal of Phytopathology, v.159, p.175-180, 2011.

BUIATE, E.A.S.; SOUZA, E.A. de; VAILLANCOURT, L.; RESENDE, I.; KLINK, U.P. Evaluation of resistance in sorghum genotypes to the causal agent of anthracnose. Crop Breeding and Applied Biotechnology, v.10, p.166-172, 2010.

CASELA, C.R.; FREDERIKSEN, R.A. Pathogenic variation in monoconidial cultures of Colletotrichum graminicola from a single lesion and from monoconidial subcultures. Fitopatologia Brasileira, v.19, p.149-153, 1994.

CASELA, C.R.; FREDERIKSEN, R.A.; FERREIRA, A.S. Evidence for dilatory resistance to anthracnose in sorghum. Plant Disease, v.77, p.908-911, 1993.

CASELA, C.R.; SANTOS, F.G.; FERREIRA, A.S. Associação de patogenicidade e diversidade fenotípica de Colletotrichum graminicola, agente causal da antracnose em sorgo. Fitopatologia Brasileira, v.25, p.517-521, 2000.

CHALA, A.; TRONSMO, A.M.; BRURBERG, M.B. Genetic differentiation and gene flow in Colletotrichum sublineolum in Ethiopia, the centre of origin and diversity of sorghum, as revealed by AFLP analysis. Plant Pathology, v.60, p.474-482, 2011.

COSTA, R.V. da; ZAMBOLIM, L.; COTA, L.V.; SILVA, D.D.; RODRIGUES, J.A.S.; TARDIN, F.D.; CASELA, C.R. Genetic control of sorghum resistance to leaf anthracnose. Plant Pathology, v.60, p.1162-1168, 2011.

FERREIRA, D.F. SISVAR: um programa para análises e ensino de estatística. Revista Symposium, v.6, p.36-41, 2008.

FREDERIKSEN, R.A. Compendium of sorghum diseases. St. Paul: American Phytopathological Society, 2000. 82p.

FREDERIKSEN, R.A.; THOMAS, M.D.; BANDYOPADHYAY, R.; MUGHOGHO, L. Variable pathogens of sorghum. In: LESLIE, J.F.; FREDERIKSEN, R.A. (Ed.). Disease analysis through genetics and biotechnology. Interdisciplinary bridges to improved sorghum and millet crops. Ames: Iowa State University, 1995. p.11-23.

GUIMARÃES, F.B.; CASELA, C.R.; SANTOS, F.G. dos; FERREIRA, A.S. Controle da antracnose do sorgo através da 
utilização de mistura de cultivares. Summa Phytopathologica, v.24, p.131-135, 1998.

LANNOU, C.; MUNDT, C.C. Evolution of a pathogen population in host mixtures: simple race - complex race competition. Plant Pathology, v.45, p.440-453, 1996.

LESLIE, J.F.; FREDERIKSEN, R.A. Variable pathogens: a scenario. In: LESLIE, J.F.; FREDERIKSEN, R.A.; BORLAUG, N. (Ed.). Disease analysis through genetics and biotechnology. Interdisciplinary bridges to improved sorghum and millet crops. Ames: Iowa State University, 1995. p.3-8.

LIMA, M.L.F.; MENEZES, M. Estudo comparativo de isolados de Colletotrichum graminicola através da análise eletroforética de padrões protéicos e isoenzimáticos. Fitopatologia Brasileira, v.27, p.12-16, 2002.

NTAHIMPERA, N.; DILLARD, H.R.; COBB, A.C.; SEEM, R.C. Anthracnose development in mixtures of resistant and susceptible dry bean cultivars. Phytopathology, v.86, p.668-673, 1996.

PEREIRA, I.S.; SILVA, D. da D.; CASELA, C.R.; TARDIN, F.D.; ABREU, M. de S. Resistência de linhagens genitoras e híbridos simples de sorgo a Colletotrichum sublineolum, agente causal da antracnose. Revista Caatinga, v.24, p.46-51, 2011.

PERUMAL, R.; MENZ, M.A.; MEHTA, P.J.; KATILÉ, S.; GUTIERREZ-ROJAS, L.A.; KLEIN, R.R.; KLEIN, P.E.; PROM, L.K.; SCHLUETER, J.A.; ROONEY, W.L.; MAGILL, C.W. Molecular mapping of $\mathrm{Cg} 1$, a gene for resistance to anthracnose (Colletotrichum sublineolum) in sorghum. Euphytica, v.165, p.597-606, 2009.

PYNDJI, M.M.; TRUTMANN, P. Managing angular leaf spot on common bean in Africa by supplementing farmer mixtures with resistant varieties. Plant Disease, v.76, p.1144-1147, 1992.
SHANER, G.; FINNEY, R.F. The effects of nitrogen fertilization on the expression of show-mildwing in knox wheat. Phytopathology, v.67, p.1051-1055, 1977.

SHARMA, H.L. A technique for identifying and rating resistance to foliar diseases of sorghum under field conditions. Proceedings of the Indian Academy of Sciences, v.42, p.271-278, 1983.

SILVA, D.D.; CASELA, C.R.; CASTRO, H.A.; SANTOS, F.G.; FERREIRA, A.S. Diversidade populacional de Colletotrichum sublineolum em seis localidades no Brasil. Summa Phytopathologica, v.34, p.149-155, 2008.

SITCH, L.; WHITTINGTON, W.J. The effect of variety mixtures on the development of swede powdery mildew. Plant Pathology, v.32, p.41-46, 1983.

TAPSOBA, H.; WILSON, J.P. Increasing complexity of resistance in host populations through intermating to manage rust of pearl millet. Phytopathology, v.89, p.450-455, 1999.

TORRES, J.C.; VENTURA, J.A. AVACPD: um programa para calcular a área e o volume abaixo da curva de progresso da doença. Fitopatologia Brasileira, v.16, p.52, 1991. Suplemento.

WANG, M.L.; DEAN, R.; ERPELDING, J.; PEDERSON, G. Molecular genetic evaluation of sorghum germplasm differing in response to fungal diseases: rust (Puccinia purpurea) and anthracnose (Collectotrichum graminicola). Euphytica, v.148, p.319-330, 2006.

WILSON, J.P. Identification of virulence in Puccinia substriata var. indica to $\mathrm{Rr}_{1}$ in pearl millet. Plant Disease, v.77, p.100, 1993.

WILSON, J.P.; HANNA, W.W.; GATES, R.N. Stability of forage yield and quality in pearl millet hybrids heterogeneous for rust resistance. Euphytica, v.72, p.163-170, 1994.

Recebido em 2 de setembro de 2011 e aprovado em 27 de janeiro de 2012

Pesq. agropec. bras., Brasília, v.47, n.2, p.173-180, fev. 2012 